\title{
Cyclic Tetranuclear and Hexanuclear Palladium(II) Complexes and Their Host-Guest Chemistry
}

\author{
Judith A. Walmsley ${ }^{*}, 1$, Shourong $\mathrm{Zhu}^{1, \dagger}{ }^{1}$, Antonio Matilla ${ }^{2}$, Tiffanee G. Donowick ${ }^{1}$, Jessica \\ E. Cramp ${ }^{1}$, Jose Manuel Tercero ${ }^{2}$, and Tatyana Dalrymple ${ }^{1}$ \\ 1 Department of Chemistry, The University of Texas at San Antonio, One UTSA Circle, San Antonio, \\ TX 78249 \\ 2 Departmento de Quimica Inorganica, Facultad de Farmacia, Universidad de Granada, Granada, \\ Spain
}

\section{Abstract}

Cyclic tetrameric complexes have been prepared by the reaction of $\mathrm{Pd}(\mathrm{en}) \mathrm{Cl}_{2}$ or $\mathrm{Pd}(\mathrm{dapol}) \mathrm{Cl}_{2}$, or their nitrato analogs, with $\mathrm{Na}_{2}\left(5^{\prime} \mathrm{GMP}\right)$ in aqueous solution, where en $=1,2$-diaminoethane, dapol $=$ 1,3-diamino-2-propanol, 5'-GMP = guanosine 5'-monophosphate. Addition of certain small molecules containing hydrophobic groups resulted in the expansion of the tetramer to a cyclic hexamer with strong bonding of one guest per hexameric host. At $\mathrm{pH} 5-6$, the guest molecule can be a cation, anion, or neutral, and those species containing trimetylsilyl and $t$-butyl groups bonded the most strongly. The size of the central cavity of the $\left[\mathrm{Pd}(\mathrm{en})\left(5^{\prime} \mathrm{GMP}\right)\right]_{6}$ host has been estimated to be $5.2 \AA$. Formation of the host-guest complex caused a large upfield shift $(\Delta \delta)$ of $2.5-2.9 \mathrm{ppm}$ in the ${ }^{1} \mathrm{H}$ NMR spectrum of the most highly affected guest protons, which were those in closest proximity to the guanine nucleobases. NOESY spectra were used to determine the interaction sites between the host and the guest. Apparent association constants determined at $26^{\circ} \mathrm{C}$ and $\mathrm{pD} 5.4$ for the $\left[\mathrm{Pd}(\mathrm{en})\left(5^{\prime} \mathrm{GMP}\right)\right]_{6}-\mathrm{DSS}$ and $\left[\mathrm{Pd}(\mathrm{en})\left(5^{\prime} \mathrm{GMP}\right)\right]_{6}-t$-butanol systems, where DSS is 3 (trimethylsilyl)-1-propanesulfonate anion, were $1.36 \pm 0.11 \times 10^{4}$ and $2.74 \pm 0.95 \times 10^{4} \mathrm{M}^{-3 / 2}$, respectively. The Pd(dapol)-5'GMP system forms hexameric host-guest complexes, similar in nature to those of the $\mathrm{Pd}(\mathrm{en})-5^{\prime}-\mathrm{GMP}$ system. The molecular and crystal structures of $\mathrm{Pd}(\mathrm{dapol}) \mathrm{Cl}_{2}$ are also reported.

\section{Introduction}

Current activity in the synthesis of cyclic and more complex polynuclear transition metal complexes has opened up a new area of host-guest chemistry. Many different transition metal ions have been found to form complexes having structures containing molecular triangles, squares, higher order cyclic species and closed structures. ${ }^{1-3}$ Cyclic compounds of Pt(II) and $\mathrm{Pd}(\mathrm{II})$ were some of the first metals investigated because their square planar geometry provides corners for the formation of complex shapes. ${ }^{4-7}$ Geometries include trimers, tetramers (molecular squares), pentamers, and hexamers ${ }^{4,6,8-10}$ as well as a few higher n-mers. ${ }^{11}$ Typically these are held together by bridging $\mathrm{N}$ donor ligands. Interest in these compounds has

\footnotetext{
*Corresponding author; Phone 210-458-5459; judith.walmsley@utsa.edu

${ }^{\dagger}$ Current address: Department of Chemistry, Shanghai University, Shanghai 200444, P. R. China

Supporting Information Available: ${ }^{1} \mathrm{H}$ NMR spectra of other host-guest complexes, additional chemical shift data, crystallographic data in CIF format, crystal packing diagram. This materials is available free of charge via the Internet at http://pubs.acs.org. Crystallographic data for the structure has been deposited with the Cambridge Crystallographic Data Center (CCDC No.: CCDC 637297). Copies of this information may be obtained free of charge from the Director, CCDC, 12 Union Road, Cambridge CB2 1EZ, U.K. (e-mail, deposit@ccdc.cam.ac.uk, or www, htpp://www.ccdc.cam.ac.uk).
} 
been driven in part by the anticancer activity of $\mathrm{Pt}$ (II) compounds and in part by the search for novel molecular architectures based on metal ions. The cyclic polynuclear metal species are frequently cationic and, in some cases, have been found to behave as hosts for anions. $3,4,6$, 12,13

Among the ligands used to bridge between the metal centers in the cyclic complexes, the nucleobases, nucleosides, and nucleotides have been frequently investigated, especially with $\mathrm{Pt}(\mathrm{II})$ and $\mathrm{Pd}(\mathrm{II}) .2,3,14$ The preferred binding site of metal ions to guanine and inosine derivatives is the $\mathrm{N} 7$ position, but $\mathrm{N} 1$ also becomes a binding site upon deprotonation. ${ }^{15}$ The formation of polymeric species, in which Pd(II) bonding is occurring at both N7 and N1 of a metal-bridging purine ring, was first proposed by Haring and Martin. ${ }^{16}$ Based on NMR and other measurements in solution, a cyclic tetramer, $\left[\mathrm{Pd}(\mathrm{en})\left(5^{\prime} \mathrm{GMP}\right]_{4}\right.$, where $5^{\prime} \mathrm{GMP}$ is guanosine 5 '-monophosphate, was later proposed by Harada and coworkers to be the polymeric species ${ }^{17}$ and the tetrameric nature (Figure 1) was later confirmed by mass spectrometry ${ }^{18}$ and potentiometric titrations. ${ }^{19} \mathrm{~A}$ crystal structure of this tetramer, either with en or any other chelating diamine and other purine nucleosides or nucleotides, has never been obtained.

However, the crystal structures of several other cyclic nucleobase-containing Pt(II) complexes have been obtained, for example $[\mathrm{Pt}(\mathrm{en})(\text { uracilate })]_{4}\left(\mathrm{NO}_{3}\right)_{4}$, which has been shown to weakly bind anions as guests in aqueous solution 13,20 and $\mathrm{Pt}(\mathrm{II})$ trimers containing bridging 1methylcytosine ${ }^{21,22}$ or 9-methyladenine. ${ }^{23}$ The structure of the cyclic hexamer $\left[\left(\mathrm{PMe}_{3}\right)_{2} \operatorname{Pt}(9\right.$ methylguanine $)]_{6}\left(\mathrm{NO}_{3}\right)_{6} \cdot 18 \mathrm{H}_{2} \mathrm{O}$ has been found to have $\mathrm{S}_{3}$ symmetry with the 9methylguanines located alternately above and below the plane of the six $\mathrm{Pt}(\mathrm{II}){ }^{8}$

The host-guest behavior of cyclic polynuclear complexes in solution has most often been investigated by NMR spectroscopy. In many cases the bridging ligands were aromatic or unsaturated molecules and ring currents or hydrophobic effects resulted in upfield shifts of the guest molecule resonances, frequently of $1 \mathrm{ppm}$ or less. ${ }^{13,24}$ In these cases the guest was usually exchanging with its counterpart in solution at such a rate that an averaged NMR resonance was observed and the apparent association constants of the cyclic host-guest systems were frequently in the range of 10 to several hundreds. ${ }^{6,20}$ Other hosts which bind the guests through strong hydrophobic interactions exhibit much larger $\Delta \delta$ values. ${ }^{25-27}$

In this paper we report the formation of host-guest complexes of $\left[\mathrm{Pd}(\mathrm{II})(\text { diamine })\left(5^{\prime} \mathrm{GMP}\right)\right]_{\mathrm{n}}$, where the diamine is 1,2-diaminoethane (en) or 1,3-diamino-2-propanol (dapol), in aqueous solution in the $\mathrm{pH}$ range of 5.5 to $7.0 .^{28}$ The guests can be cationic, anionic, or neutral with a high degree of hydrophobic character. They bind strongly to the host in a 1:1 mole ratio, are in slow chemical exchange with uncomplexed guest molecules, and exhibit very large upfield chemical shifts (2.5-3.0 ppm) for the most highly affected protons in the NMR spectra. The $\left[\mathrm{Pd}(\mathrm{en})\left(5^{\prime} \mathrm{GMP}\right]_{4}\right.$ host expands to a hexamer upon incorporation of the guest. This appears to be a templating effect. The Pd(dapol)-5'GMP system is more complex, but also forms hexameric host-guest complexes in some cases.

\section{Experimental Section}

\section{Materials}

$\mathrm{Na}_{2}$ (5'GMP) and $\mathrm{H}_{2}$ (5'GMP) were purchased form Sigma. $\mathrm{Pd}(\mathrm{en}) \mathrm{Cl}_{2}$ was purchased from Aldrich Chemical Co., or prepared from $\mathrm{K}_{2} \mathrm{PdCl}_{4}$ and 1,2-diaminoethane ${ }^{29}$ and [Pd(en) $\left.\left(\mathrm{H}_{2} \mathrm{O}\right)_{2}\right]\left(\mathrm{NO}_{3}\right)_{2}$ solutions were prepared according to the published procedure. ${ }^{30}$ Sodium 3(trimethylsilyl)-1-propanesulfonate (DSS, Wilmad) and sodium 3-(trimethysilyl)propionate$\mathrm{d}_{4}$ (TSP, Stohler Isotope Chemicals, Waltham, MA), 1-butanol (Fisher Scientific), 2-propanol (Mallinckrodt) were used as received. All other chemicals were obtained from Aldrich and used as received. The concentrations of 5'GMP solutions were determined spectroscopically 
$\left(\lambda=252 \mathrm{~nm}, \varepsilon=1.37 \times 10^{4} \mathrm{M}^{-1} \mathrm{~cm}^{-1}\right)$. Stock solutions were prepared by adding a weighed amount of $\mathrm{Pd}(\mathrm{en}) \mathrm{Cl}_{2}$ to a $5^{\prime} \mathrm{GMP}$ solution to give the desired concentration and mole ratio of $\mathrm{Pd}(\mathrm{en}): 5^{\prime} \mathrm{GMP}$, or by mixing $\left[\mathrm{Pd}(\mathrm{en})\left(\mathrm{H}_{2} \mathrm{O}\right)_{2}\right]\left(\mathrm{NO}_{3}\right)_{2}$ and $5^{\prime} \mathrm{GMP}$ solutions

$\operatorname{Pd}\left(\right.$ dapol) $\mathrm{Cl}_{2}$ was synthesized by slowly adding, with stirring, $100 \mathrm{~mL}$ of an aqueous solution containing $4.5 \mathrm{mmol}$ of dapol to $100 \mathrm{~mL}$ of a warm solution of $4.5 \mathrm{mmol} \mathrm{K}_{2} \mathrm{PdCl}_{4}$ in water. After reaction, the clear solution ( $\mathrm{pH}$ 5.5-6.0) was allowed to evaporate at room temperature. Orange crystals were separated by filtration, washed with cold water and air dried. Yield 75\%. Calc. for Pd(dapol) $\mathrm{Cl}_{2}$ : C 13.47; H 3.77; N 10.48. Found: C 13.52; H 3.79; N 10.38.

\section{Methods}

NMR Studies-Spectra of ligands and complexes were recorded on a Varian INOVA 500 $\mathrm{MHz}$ spectrometer in $\mathrm{D}_{2} \mathrm{O}$ with temperature control. Spectra of solutions were taken immediately after preparation and again later to check for completeness of reaction, which was typically complete in 3 days or less. ${ }^{1} \mathrm{H}$ NMR spectra were referenced to the HOD line at 4.800 ppm and ${ }^{31} \mathrm{P}$ NMR spectra were referenced to external $85 \% \mathrm{H}_{3} \mathrm{PO}_{4}$. The tetrametylammonium ion $\left(\mathrm{TMA}^{+}\right)$was used as an internal reference in the variable temperature experiments for the determination of $\Delta \mathrm{H}$ and $\Delta \mathrm{S}$. Although $\mathrm{TMA}^{+}$can be a guest in the host-guest complex, at the $100 \mathrm{mM}$ DSS concentration used for the experiments, it is expected to be negligible. A DSS line at $0.64 \mathrm{ppm}$ obscures any possible $\mathrm{TMA}^{+}$guest.

Determination of Apparent Equilibrium Constants-The $K_{\text {assoc }}^{\prime}$ were determined at $26{ }^{\circ} \mathrm{C}$ from integrated intensity ${ }^{1} \mathrm{H}$ NMR data. $\mathrm{Pd}(\mathrm{en}) \mathrm{Cl}_{2}$-GMP (1:1) samples $(20 \mathrm{mM}, 1.00$ $\mathrm{mL}$ each) were transferred into NMR tubes and $0-200 \mu \mathrm{L}$ of 0.5 or $1.0 \mathrm{M}$ sodium 3-

(trimethylsilyl)-1-propanesulfonate or $t$-butanol in $\mathrm{D}_{2} \mathrm{O}$ were added. The concentrations were corrected for dilution. The samples were allowed to equilibrate at room temperature for 3 days before acquiring the spectra. The total integrated intensity/proton for 5'GMP was obtained by integrating the whole $\mathrm{H} 1^{\prime}$ region of $5^{\prime} \mathrm{GMP}$. The concentrations of $5^{\prime} \mathrm{GMP}$ in the hexameric and in the tetrameric species in the solutions were determined from the fraction of the (individual integrated intensitiy/total integrated intensity per $\mathrm{H}) \times\left(\right.$ total $\left.\left[5^{\prime} \mathrm{GMP}\right]\right)$. The concentrations of the DSS or $t$-butanol in the host-guest complex and of free DSS or $t$-butanol were determined from the integrated intensity of the $\mathrm{CH}_{3}$ groups. The concentration of $[\mathrm{Pd}(\mathrm{en})$ $\left.\left(5^{\prime} \mathrm{GMP}\right)\right]_{4}$ is $1 / 4$ of the total $\left[5^{\prime} \mathrm{GMP}\right]$ in tetramer and $\left[\mathrm{Pd}(\mathrm{en})\left(5^{\prime} \mathrm{GMP}\right)\right]_{6}(\mathrm{DSS})$ is $1 / 6$ of the total [5'GMP] in hexamer.

$\mathrm{Pd}($ dapol $) \mathrm{Cl}_{2}$ Crystal Structure Determination-A suitable crystal of this compound was mounted on a glass fiber and used for data collection at 293(2) K on a STOE-Siemens AED2 diffractometer. The crystallographic data are given in Table 1. The structure was solved by direct methods ${ }^{31}$ and refined by full-matrix least-squares techniques ${ }^{32}$ on $\mathrm{F}^{2}$. Hydrogen atoms were treated as fixed contributions in positions determined experimentally from difference maps. Molecular graphics were generated with PLATON. ${ }^{33}$

\section{Results and Discussion}

All of the information to date on the Pd(en)-5'GMP and Pd(dapol)-5'GMP systems has been obtained from measurements in aqueous solution because these systems have defied all attempts to obtain crystals suitable for X-ray structure determination. Mass spectrometry results have been unhelpful for the most part, although we did observe the peak at one-quarter $\mathrm{m} / \mathrm{z}^{+}$of the $\left[\mathrm{Pd}(\mathrm{en})\left(5^{\prime} \mathrm{GMP}\right)\right]_{4}$ parent ion, as did Sheldrick's group. ${ }^{18} \mathrm{MS}$ experiments with host-guest complexes gave very complex spectra, which did not provide any meaningful information. 
In the Pd(en)-5'GMP system at $\mathrm{pH}>5$, the $5^{\prime} \mathrm{GMP}$ ligand bridges between two $[\mathrm{Pd}(\mathrm{en})]^{2+}$ groups via the $\mathrm{N} 7$ and $\mathrm{N} 1$ positions (Figure 1). We have discovered that this system and those of $\mathrm{Pd}(\mathrm{en})\left(\mathrm{NO}_{3}\right)_{2}-5^{\prime} \mathrm{GMP}$ and $\mathrm{Pd}(\mathrm{dapol}) \mathrm{Cl}_{2}-5^{\prime} \mathrm{GMP}$ in aqueous solution exhibit a highly versatile host-guest chemistry. The unusual feature of these host-guest complexes is the ability to strongly bond a variety of guests, which resulted in very large upfield shifts $(\Delta \delta=2.5-3.0$ ppm) of the most highly affected protons. (Table 2). The chemical shifts of the bonded and free guest molecules were concentration and temperature independent, which indicated that they were in slow exchange.

The similarity in the $\Delta \delta$ values for $\mathrm{CH}_{3}$ groups of all of the guest compounds has been interpreted as a result of hydrophobic interactions between the guanine bases of the Pd complex and the guest molecules or ions. The differences in the $\Delta \delta$ values were interpreted as a function of the fit of the guest in the host and as differences in the strengths of the hydrophobic interactions with the host. Typically in host-guest compounds where ionic species are involved, all of the guests in a given host will have the same charge characteristic. However, in the Pd (en)-5'GMP and Pd(dapol)-5'GMP systems, the guest can be a cation, anion, or neutral molecule, suggesting that the $\mathrm{Pd}(\mathrm{II})$ host is a neutral or near neutral species at $\mathrm{pH}$ 5-6. This was supported by ${ }^{1} \mathrm{H}$ and ${ }^{31} \mathrm{P}$ NMR of $\left[\mathrm{Pd}(\mathrm{en})\left(5^{\prime} \mathrm{GMP}\right)\right]_{4}$ which showed that the $\mathrm{N}(1)$ site had been deprotonated as a result of the $N 7-N 1$ bridging and that the phosphate group was monoprotonated (-1charge), resulting in an overall 2-charge for the 5'-GMP moiety.

\section{Pd(en)-5'GMP System}

The ${ }^{1} \mathrm{H}$ NMR spectrum indicated the presence of only one kind of environment for the 5 'GMP in the cyclic tetramer, $\left[\mathrm{Pd}(\mathrm{en})\left(5^{\prime} \mathrm{GMP}\right)\right]_{4}$. The $\mathrm{H} 8$ resonance was located at $8.55 \mathrm{ppm}$ and the $\mathrm{H} 1^{\prime}$ at $6.55 \mathrm{ppm}$ at pD 5.4 (Figure 2A), compared to 8.20 and $5.95 \mathrm{ppm}$, respectively, in $\mathrm{Na}_{2}$ (5'GMP). Two isomers are possible for this system: (1) -N1-Pd-N7-; (2) two corners as N7-Pd-N7- and two corners as -N1-Pd-N1-. Previously we had proposed that isomer (1) was the likely structure. However, upon close examination of the en region in the ${ }^{1} \mathrm{H}$ and ${ }^{13} \mathrm{C}$ spectra, it appeared that there were two environments for $\mathrm{Pd}(\mathrm{en})^{2+}$, suggesting isomer (2) configuration (Figure 1). Based on modeling, the en in the -N7-Pd- N7- corners has restricted motion due to steric crowding, which results in the AA 'BB' pattern centered at $2.85 \mathrm{ppm}$ (Figure 2A). The singlet at $2.80 \mathrm{ppm}$ arises from the more flexible -Nl-Pd-Nl-corners, and disappears upon formation of the host-guest complexes and concomitant change in structure.

$\left[\mathrm{Pd}(\mathrm{en})\left(5^{\prime} \mathrm{GMP}\right)\right]_{4}$ is thermally stable between $2-66{ }^{\circ} \mathrm{C} .{ }^{19}$ Even at $80{ }^{\circ} \mathrm{C}$ at $\mathrm{pD} 5.4$ the ${ }^{1} \mathrm{H}$ NMR spectrum contained an appreciable amount of tetramer plus an indeterminate amount of other species present as very broad humps in the baseline. The AA 'BB' multiplet for the en ligand in the tetramer continued to exist to the extent that the tetramer was present, although it broadened slightly with increasing temperature and there were also small changes in the pattern. We believe that the lack of flexibility of the this en multiplet at elevated temperatures is evidence for structural rigidity of the tetramer, arising in part from the rigid 5'GMP bridging ligand.

Since macrochelation of phosphate in metal complexes is known to occur in some cases, ${ }^{18}$, 34 the ${ }^{31} \mathrm{P}$ NMR spectrum of the cyclic tetramer was examined. Any significant interaction between the $\mathrm{Pd}(\mathrm{en})^{2+}$ portion of the tetramer and the phosphate group of the $5^{\prime} \mathrm{GMP}$ can be discounted because the ${ }^{31} \mathrm{P}$ chemical shift of $20 \mathrm{mM} \mathrm{Na}_{2}\left(5^{\prime} \mathrm{GMP}\right)$ is $1.21 \mathrm{ppm}$, compared to $1.65 \mathrm{ppm}$ for $\left[\mathrm{Pd}(\mathrm{en})\left(5^{\prime} \mathrm{GMP}\right)\right]_{4}$ at $\mathrm{pD} 5$. Although the two values differ by a small amount (for ${ }^{31} \mathrm{P}$ spectra), a much larger change is expected for $\mathrm{Pd}(\mathrm{II})-\mathrm{OPO}_{3} \mathrm{R}$ bonding, as was observed in a Co ${ }^{\text {III- }} 5^{\prime}$ GMP complex $(\delta=12 \mathrm{ppm}) .{ }^{35}$

For most bonded guests, an additional weak resonance or resonances were observed within $0.02 \mathrm{ppm}$ of the major upfield resonance. It was assumed that these were the result of small 
amounts of a very slightly different guest conformer in the host-guest complex and they were included in integrated intensities, except where noted.

\section{$\left[\mathrm{Pd}(\mathrm{en})\left(5^{\prime} \mathrm{GMP}\right)\right]_{4}+$ Guests}

DSS as Guest: When DSS was added to a solution of $\left[\operatorname{Pd}(\mathrm{en})\left(5^{\prime} \mathrm{GMP}\right)\right]_{4}$, new lines appeared for both the Pd(en)-5'GMP complex and the bonded DSS (Table 2, Figure 2B). Upon the addition of a large excess of DSS, the $\mathrm{H} 8$ and $\mathrm{H} 1$ ' resonances of the unreacted tetramer decreased and essentially disappeared at a 1:5 mole ratio of starting tetramer:DSS. The two resonances of the host in the host-guest complex seen in the H8 and H1' regions of the 5'GMP were always of equal intensity regardless of concentration, temperature, and host to guest mole ratio, which suggested that they were two different environments within a single species rather than two different species. The alternative interpretation that the two lines were the result of diastereomer formation was discounted because only single lines were observed for the guest. ${ }^{31} \mathrm{P}$ NMR spectra also showed two different environments for the phosphate, with resonances at 1.43 and $1.38 \mathrm{ppm}$ and the unreacted tetramer phosphates at $1.65 \mathrm{ppm}$ (Figure 3 ). In this regard, the ${ }^{13} \mathrm{C}$ NMR spectra were the most revealing, showing three resonances for each 5'GMP carbon, of which the most upfield one was the host tetramer and the other two were from the hexameric host-DSS complex. However, only a single carbon resonance was observed for the guest trimethylsilyl group ( $-3.05 \mathrm{ppm}$ ) and each of the $\beta$ and $\gamma \mathrm{CH}_{2}$ groups $\left(15.71,20.82 \mathrm{ppm}\right.$ ), which were shifted upfield as observed in the ${ }^{1} \mathrm{H}$ spectrum ( free DSS $\left.{ }^{13} \mathrm{C}: 0,17.69,21.80,57.08 \mathrm{ppm}\right)$.

Two experiments were carried out to determine the stoichiometry of bonded DSS to host Pd (en)-5'GMP. In one case, solutions were prepared containing various amounts of $\left[\operatorname{Pd}(\mathrm{en})\left(5^{\prime}\right.\right.$ GMP) $]_{4}$ in a $10 \mathrm{mM}$ DSS solution. In the second case, the concentration of DSS was varied in a $20 \mathrm{mM}\left[\mathrm{Pd}(\mathrm{en})\left(5^{\prime} \mathrm{GMP}\right)\right]_{4}$ solution. The integrated intensities of the host 5'GMP H1' resonance and the strongly predominant DSS resonance at $-2.76 \mathrm{ppm}$ were plotted, taking into account the 1:9 ratio of $\mathrm{H1}^{\prime}:\left(\mathrm{CH}_{3}\right)_{3} \mathrm{Si}$ protons. The slope of the lines gave the stoichiometry of $\mathrm{Pd}(\mathrm{en})\left(5^{\prime} \mathrm{GMP}\right)$ host to DSS guest as $5.9+/-0.4$ and $6.0+/-0.3$ for the two experiments, respectively (Figure 4$)$. From this it was concluded that the original $\left[\mathrm{Pd}(\mathrm{en})\left(5^{\prime} \mathrm{GMP}\right)\right]_{4}$ species had expanded to a hexamer via a templating effect of the added DSS. Expansion of a host upon inclusion of a guest or other reactant has also been observed in other molecular systems.

36-39 It should be noted that in addition to the major 6:1 host-guest complex, a minor complex of unknown structure and stoichiometry existed in the solutions.

Not only were the methyl protons of guest DSS shifted upfield, the methylene protons also were shifted upfield, but to a lesser extent. Each of the $\mathrm{CH}_{2}$ groups appeared as a weak, broad resonance containing two maxima $\left(\gamma-\mathrm{CH}_{2},-0.91,-1.06 \mathrm{ppm}(\Delta \delta=1.4\right.$ from free DSS)); $\beta$ $\mathrm{CH}_{2}, 1.19,1.09 \mathrm{ppm}(\Delta \delta=0.4)$ ), which indicated that each of the protons in a given $\mathrm{CH}_{2}$ had a slightly different environment, probably with respect to the rotational position of the DSS chain in the cavity. The methylene assignments were confirmed by a COSY experiment. The decreasing $\Delta \delta$ s showed that these protons were increasingly farther away from the primary host-guest interaction site,

The host-guest behavior was strongly $\mathrm{pH}$ dependent as shown by ${ }^{1} \mathrm{H}$ NMR measurements on a $10 \mathrm{mM} \mathrm{Pd}(\mathrm{en})\left(5^{\prime} \mathrm{GMP}\right)$ solution containing 1.0 mM DSS. Bonding of DSS was first observed at $\sim \mathrm{pH} 4.0$ and reached a maximum at $\mathrm{pH} 5.0-5.5$ before decreasing once again at $\mathrm{pH}$ 6.0. By pH 7.7, only a small fraction of the DSS was bonded as host. The Pd(dapol)-5'-GMP system with DSS showed the same behavior. The $\mathrm{pH}$ dependence of host-guest formation appeared to be a function of two factors: the degree of protonation of the phosphate and the $\mathrm{pK}_{\mathrm{a}}$ of the N1$\mathrm{H}$ in the presence of $\mathrm{Pd}(\text { diamine })^{2+}$ complex. At low $\mathrm{pH}$, the $\mathrm{N} 1$ remained protonated and the cyclic $\mathrm{Pd}(\mathrm{II}) \mathrm{n}$-mer did not form, at $\mathrm{pH} \sim 5-6$ the $\mathrm{N} 1-\mathrm{H}$ was dissociated and the phosphate groups were monoprotonated, ${ }^{40}$ and at $\mathrm{pH}$ above $\sim 6.5$ the tetramer is still stable, but the 
phosphates became completely deprotonated. Therefore, it was concluded that H-bonding between monoprotonated phosphate and the sulfonate group in the host-guest complex, possibly mediated by water molecules, stabilized the bonding of the DSS by reducing the rate of exchange of free and bonded guest. This would have little effect on the ${ }^{31} \mathrm{P}$ chemical shifts. ${ }^{41}$ Alternatively, the conformation of the now dianionic phosphates is different at the higher $\mathrm{pH}$ as a result of increased repulsion.

In order to determine the interaction sites of the DSS moiety, NOESY experiments were carried out. The spectra contained crosspeaks between the DSS methyl protons and the $\mathrm{H} 8$ and $\mathrm{H}^{\prime}$ ' of the $\left[\mathrm{Pd}(\mathrm{en})\left(5^{\prime} \mathrm{GMP}\right)\right]_{6}$ host complex (Figure 5), with the stronger interaction with the H1'. This placed the $\mathrm{CH}_{3}$ group in or near the center of the cyclic $\left[\mathrm{Pd}(\mathrm{en})\left(5^{\prime} \mathrm{GMP}\right)\right]_{6}$ species and in close proximity to the guanine of the $5^{\prime}$ GMP ligands. The NOESY also showed that there was slow exchange between the guest DSS and free DSS. Intramolecular 5'GMP NOE's were observed between the $\mathrm{H} 8$ and the $\mathrm{H}^{\prime}$, but stronger NOEs were observed between the $\mathrm{H} 8$ and the $\mathrm{H} 2^{\prime}$ and $\mathrm{H}^{3}$ ', indicating a predominantly anti conformation about the glycosidic bond.

Based on the above data, it is proposed that the $\left[\mathrm{Pd}(\mathrm{en})\left(5^{\prime} \mathrm{GMP}\right)\right]_{6}-\mathrm{DSS}$ complex has the structure shown in Figure 6A in which the directionality of the 5'GMP ligands alternates around the hexameric ring such that the $\mathrm{C}=\mathrm{O}$ group can be considered to be up or down around the cycle. As a result of the size of the DSS, only one DSS can be accommodated per host hexamer (Figure 6B), creating the two different environments in the $\left[\mathrm{Pd}(\mathrm{en})\left(5^{\prime} \mathrm{GMP}\right)\right]_{6}$-DSS structure and resulting in the two equal intensity lines for the $5^{\prime}-\mathrm{GMP} \mathrm{H}, \mathrm{H} 1{ }^{\prime},{ }^{31} \mathrm{P}$, and ${ }^{13} \mathrm{C}$ resonances in the host-guest spectra.

Butanol as Guest: All three isomers of butanol formed host-guest complexes with the Pd (en)-5'GMP moiety. The $\Delta \delta$ between the bonded and the free butanol became smaller in the order $t->i->n$-butanol, that is, as the bulkiness of the isomer decreased. This was ascribed to a looser fit of the less-branched isomers in the host. The effect of adding $t$-butanol to a $20 \mathrm{mM}$ $\left[\mathrm{Pd}(\mathrm{en})\left(5^{\prime} \mathrm{GMP}\right)\right]_{4}$ solution is shown in Figure 7 . With $20 \mathrm{mM} t$-butanol essentially all of the tetrameric host had been converted into the host-guest complex, as shown by the disappearance of the $\mathrm{H} 1^{\prime}$ resonance of the tetramer at $6.55 \mathrm{ppm}$ and the presence of the hexamer line at 6.03 $\mathrm{ppm}$. A value for the Pd: $t$ - $\mathrm{BuOH}$ ratio of $5.9 \pm 0.7$ was determined from two independent data sets (12 points total). Integration of the hexamer $5^{\prime}$ GMP lines and the more intense bonded $t$ butanol line at $-1.614 \mathrm{ppm}$ was less clear cut than in the DSS guest system because of the overlap of a weak, broad line on the upfield side of the $t$-butanol guest. In addition to the major guest line $(-1.614 \mathrm{ppm})$ there were several weak minor resonances $(-1.583,-1.620,-1.625$ $\mathrm{ppm})$ due to guest $t$-butanol.

In contrast to the $\left[\mathrm{Pd}(\mathrm{en})\left(5^{\prime} \mathrm{GMP}\right)\right]_{6}$ - DSS system, there was only one environment for the $5^{\prime}$ GMP in the hexameric host. It is thought that this was the result of the approximately spherical nature of the $t$-butanol molecule. It cannot be attributed to an averaging of the $5^{\prime} \mathrm{GMP}$ signals because the chemical shifts of the bonded and free $t$-butanol resonances were invariant with concentration.

The ${ }^{1} \mathrm{H}$ NOESY spectrum of $20 \mathrm{mM}$ Pd(en)( $\left.5^{\prime} \mathrm{GMP}\right)$ containing $10 \mathrm{mM} t$-butanol was obtained with mixing times of $0.50 \mathrm{~s}$ and $1.00 \mathrm{~s}$ and was very similar to that with DSS as the guest, although the interactions were considerably weaker ( Supporting Information). The $t$-butanol interaction with $\mathrm{H} 8$ was much weaker than with the $\mathrm{H} 1$ '. Therefore the $t$-butanol appeared to be located in the central cavity of the host in much the same way as DSS.

iso-Butanol (2-methyl-1-propanol): As for the host-guest complexes discussed so far, the stoichiometry was one $i-\mathrm{BuOH} /$ hexamer, although the host to guest integration was less certain because of complete overalp of minor species with the major species. A significant difference 
with the $i-\mathrm{BuOH}$ guest was the observation of two resolved doublets of approximately equal intensity located at -1.85 and $-1.87 \mathrm{ppm}$ for the methyl groups of the $\left(\mathrm{CH}_{3}\right)_{2} \mathrm{CH}$ - segment (Figure 8). These resonances did not shift with changes in host or guest concentrations. Each doublet had a coupling constant of $7.0 \mathrm{~Hz}$ each, the same as that for the methyl groups of free $i$ - $\mathrm{BuOH}$. Although there were two methyl doublets, only one guest $\mathrm{CH}$ heptet was present at $-1.25 \mathrm{ppm}$, which suggested that for a given guest $i-\mathrm{BuOH}$ there were two slightly different, but fixed environments for each of the methyl groups. This was also reflected in the $\mathrm{CH}_{2}$ protons, which were also nonequivalent.

2-Propanol as a Guest: The $\left[\mathrm{Pd}(\mathrm{en})\left(5^{\prime} \mathrm{GMP}\right)\right]_{6}-2$-propanol system at $\mathrm{pH}$ 5.0-5.5 was not as well defined as the other host-guest complexes. Reminiscent of the system with $i-\mathrm{BuOH}$, two resonances of equal intensity were observed in the upfield region at -1.69 and $-1.75 \mathrm{ppm}$.

However, these were weak, broad and the coupling to the $\mathrm{CH}$ was unresolved. The separation between the two methyl resonances was $28 \mathrm{~Hz}$, too large to be a coupling constant for a methyl group. The $\mathrm{H} 8$ and $\mathrm{H}^{\prime}$ chemical shifts of the host [Pd(en)(5'GMP)] were located at 8.61 and $6.04 \mathrm{ppm}$, respectively, as observed for the hexameric host in the other host-guest complexes. When it is assumed that both upfield guest resonances were arising from the same molecule, integrated intensities gave an approximate stoichiomety of one 2-propanol per hexamer. From the broadness of these resonances, it appeared that they had some freedom of motion within the central cavity.

Other Guests: Of the other guests listed in Table 2, the ${ }^{1} \mathrm{H}$ NMR of the host $\left[\operatorname{Pd}(\mathrm{en})\left(5^{\prime}\right.\right.$ GMP) $]_{6}$ with TSP (3-trimethysilylpropionate) also exhibited two environments. That the behavior of DSS and TSP were similar is not surprising because they have similar sizes and shapes, the same trimethysilyl hydrophobic group, and they each contain an anionic tail of ${ }^{-} \mathrm{SO}_{3}{ }^{-}$or $-\mathrm{CO}_{2}{ }^{-}$. At $\mathrm{pH}$ 5.0-5.5 these tails are capable of hydrogen bonding to the monoprotonated phosphate groups.

The unusual strength of the host-guest hydrophobic interactions was highlighted by the ability of $\left[\mathrm{Pd}(\mathrm{en})\left(5^{\prime} \mathrm{GMP}\right)\right]_{6}$ to bond tetramethylsilane (TMS) in aqueous solution. It had not been anticipated that a molecule with such insolubility in water would behave as a guest. This hostguest complex was prepared by adding neat TMS to a $\left[\mathrm{Pd}(\mathrm{en})\left(5^{\prime} \mathrm{GMP}\right)\right]_{4}$ solution and only bonded guest TMS was observed in the aqueous phase.

The tetramethylammonium ion also bonded well in the center of the Pd(en)(5'GMP) nmer as shown by the large upfield shift of the methyl protons in the host-guest complex. Although it might seem more reasonable for the $\mathrm{TMA}^{+}$ion to interact with the negative phosphate groups, it is known that the interaction of this cation with 5'AMP and 5'GMP is electrostatic only ${ }^{42}$ and that it does not affect the phosphate chemical shift in aqueous solution. ${ }^{43}$ On the other hand, the tetrabutylammonium ion did not bond at all; apparently it is too large to fit in the cavity.

Association Constants-The apparent association constants, $K_{\text {assoc }}^{\prime}$, were determined at $26^{\circ} \mathrm{C}$ for the $\left[\mathrm{Pd}(\mathrm{en})\left(5^{\prime} \mathrm{GMP}\right)\right]_{6}-\mathrm{DSS}$ system at pD 5.4 and 6.5 , and for the $\left[\mathrm{Pd}(\mathrm{en})\left(5^{\prime}\right.\right.$ GMP) $]_{6}-t$-butanol system at $\mathrm{pD} 5.4$ (Table 3 ). These are based on the equations:

$3 / 2\left[\mathrm{Pd}(\mathrm{en})\left(5^{\prime} \mathrm{GMP}\right)\right]_{4}+$ guest $\rightleftharpoons\left\{\left[\mathrm{Pd}(\mathrm{en})\left(5^{\prime} \mathrm{GMP}\right)\right]_{6}\right.$ (guest) $\}$

Eq. 1

$K_{\text {assoc }}^{\prime}=\left\{\left[\mathrm{Pd}(\mathrm{en})\left(5^{\prime} \mathrm{GMP}\right)\right]_{6}(\right.$ guest $\left.)\right\} /\left\{\left[\mathrm{Pd}(\mathrm{en})\left(5^{\prime} \mathrm{GMP}\right)\right]_{4}{ }^{3 / 2}\right\}[$ guest $]$ 
Other models used in an attempt to fit the experimental data were monomer $\rightarrow$ hexamer host and hexamer $\rightarrow$ hexamer host, but the only model that reasonably fit was the tetramer hexamer $\rightarrow$ host. This was strongly supported by the disappearance of the tetramer $\mathrm{H} 8$ and $\mathrm{H}^{\prime}$ resonances upon reaction with guest and upon the stoichiometry determined for the host-guest complexes.

In part, the uncertainties in the $K_{\text {assoc }}^{\prime}$ values arise from the presence of additional weak lines in the most upfield guest protons. With DSS as guest, additional small resonances that occurred within $\pm 0.02 \mathrm{ppm}$ of the major upfield guest had a relative intensity $\sim 0.09$ of the major resonance and were considered as part of the host-guest complex. However, in the case of $t$ $\mathrm{BuOH}$ guest where other additional upfield lines made up approximately $25 \%$ of the total reacted $t-\mathrm{BuOH}$ intensity, these lines were excluded in the calculation for the association constant. The Gibb's free energies for the $\left[\mathrm{Pd}(\mathrm{en})\left(5^{\prime} \mathrm{GMP}\right)\right]_{6}-\mathrm{DSS}$ system at pD 5.4 and 6.5 were determined from the $K_{\text {assoc }}^{\prime}$ measured at $3,26,50$ and $78^{\circ} \mathrm{C}$. The equivalent variable temperature experiment was not done for $t$-butanol because of the considerable uncertainty in the $K_{a s s o c}^{\prime}$ at room temperature.

\section{Pd(dapol)-5'GMP System}

When the ethylenediamine bidentate ligand on the Pd(II) was replaced by the 1,3-diamino2propanol ligand, the same host-guest behavior was observed with the resonance(s) of the bonded guest occurring upfield of the free guest molecule by 2.8-3.0 ppm (Table 2). However, this system was considerably more complex than the $\left[\operatorname{Pd}(\mathrm{en})\left(5^{\prime} \mathrm{GMP}\right)\right]_{4}$ system and it did not appear to self-assemble into one single species, as shown by considerable overlap of resonances in all regions of the ${ }^{1} \mathrm{H}$ NMR spectrum (Figure 9A). We suspect a possible interaction between the dapol $\mathrm{OH}$ and the $\mathrm{Pd}(\mathrm{II})$ center, but have no evidence for this. In most cases, addition of the guest resulted in significant simplification of the spectrum so that the host-guest spectrum was analogous to that obtained for the $\left[\mathrm{Pd}(\mathrm{en})\left(5^{\prime} \mathrm{GMP}\right)\right]_{4}$ system with the same guest. The $\mathrm{Pd}$ (II): guest mole ratio was determined to be 6:1 with 2-PrOH as the guest (Figure 9B). It is concluded that in the $\mathrm{Pd}(\mathrm{dapol})-5^{\prime} \mathrm{GMP}$ system the guest is absolutely required for the formation of the cyclic polynuclear host.

\section{Crystal Structure of $\mathrm{Pd}($ dapol $) \mathrm{Cl}_{2}$}

It was hoped that the crystal structure would provide a clue to the reason for the difference in behavior of the $\mathrm{Pd}(\mathrm{en})^{2+}$ and $\mathrm{Pd}(\mathrm{dapol})^{2+}$ groups with 5'-GMP, but that was not the case. Pd (dapol) $\mathrm{Cl}_{2}$ adopts a square planar four coordinate geometry with two cis positions occupied by the nitrogen atoms of the dapol ligand and the other two by chloride ions (Figure 10). Crystallographic data are given in Table 1. Selected bond lengths and angles (Table 4) are similar to those reported for analogous compounds..$^{30,44}$ The palladium atom and the four donor atoms are coplanar with Pd located $0.0072 \AA$ from the mean plane of the four donors atoms. The metal atom and the dapol ligand form a six-membered chelate ring adopting a chair conformation.

The molecules are arranged in double layers in the crystal, with Pd atoms stacked vertically (Figure S12 Supp. Material). Molecules in a given layer are linked together by hydrogen bonds between the $\mathrm{OH}$ of one complex and the $\mathrm{N}$ atoms in two other molecules (Table 5). Two layers are stacked on each other and held together by $\mathrm{N}-\mathrm{H} \cdots \mathrm{Cl}$ hydrogen bonds between amine groups of the dapol ligands and the $\mathrm{Cl}$ ions of complexes in the adjacent layer. The molecules in Layer 2 are oriented $180^{\circ}$ with respect to the molecules in Layer 1 . Hydrophobic interactions between the en ligands connect the 2D layers, generating a 3D network. 


\section{Conclusions}

$\left[\mathrm{Pd}(\mathrm{en})\left(5^{\prime} \mathrm{GMP}\right)\right]_{4}$ was formed by self-assembly upon mixing of aqueous solutions of the Pd $(\mathrm{en})^{2+}$ complex with $5^{\prime} \mathrm{GMP}$ at $\mathrm{pH}>4.5$. Upon the introduction of a small organic molecule with hydrophobic interaction sites, the tetramers spontaneously expanded to form a hexamer with one guest molecule strongly incorporated into the central cavity. The ability of the hosts to bond guest molecules of varying charge or no charge is thought to reflect the apparent neutrality of the host at $\mathrm{pH}$ 5.0-5.5. We feel that the ease with which the tetramer expanded to the hexamer might be related to unfavorable steric interactions of the 5'GMP amino groups at the $\mathrm{Nl}$-Pd-Nl corners in the tetramer, rendering the expansion in the presence of a templating agent enegetically favorable. The relatively strong bonding of the guest compared to many host-guest complexes and the sharpness of the NMR resonances is an indication that the cyclic structure of the host is probably fairly rigid. We estimate the size of the cavity of the hexamer to be approximately $5.2 \AA$ from the diameter of trimethylsilane with spherical symmetry.

From the NMR studies, it is not clear whether or not a cyclic tetramer is formed in the Pd (dapol)-5'GMP system, although $\mathrm{pH}$ titrations at $1 \mathrm{mM}$ indicated that it was the major species at $\mathrm{pH}$ 6.0-10. ${ }^{19}$ Nontheless, it showed the same type of hexamer host-guest chemistry as the $\left[\mathrm{Pd}(\mathrm{en})\left(5^{\prime} \mathrm{GMP}\right)\right]_{6}$ system. We postulate that the templating effect of the guest leads to the formation of a host-guest complex which is more stable than a cyclic $\left[\mathrm{Pd}(\mathrm{dapol})\left(5^{\prime} \mathrm{GMP}\right)\right]_{4}$.

Attempts to prepare the same cyclic tetramer with Pt(II) complexes have been unsuccessful. This is most likely because the slow kinetics of $\mathrm{Pt}(\mathrm{II})$ reaction leads to the formation of a thermodynamically stable 1:2 (Pt:5'GMP) complex instead. ${ }^{45}$

\section{Supplementary Material}

Refer to Web version on PubMed Central for supplementary material.

\section{Acknowledgements}

The authors thank the National Institutes of Health (SCORE, grant S06-08194; MARC, grant GM07717; RISE GM60655), Welch,Foundation, the Spanish government for a Visiting Professorship for AM, and The University of Texas at San Antonio for support to SZ.

\section{References}

1. Thompson LK. Coord. Chem. Rev 2002;233-234:193-206.

2. Navarro JAR, Barea E, Galindo MA, Salas JM, Romero MA, Quiros M, Masciocchi N, Galli S, Sironi A, Lippert B. J. Solid State Chem 2005;178:2436-2451.

3. Navarro JAR, Lippert B. Coord. Chem. Rev 2001;222:219-250.

4. Fujita M, Tominaga M, Hori A, Therrien B. Accts. Chem. Res 2005;38:371-380.

5. Kaiser A, Baeuerle P. Topics in Current Chemistry 2005;249:127-201.

6. Schnebeck R-D, Freisinger E, Glahe F, Lippert B. J. Am. Chem. Soc 2000;122:1381-1390.

7. Jude H, Sinclair DJ, Das N, Sherburn MS, Stang PJ. J.Org. Chem 2006;71:4155-4163. [PubMed: 16709055]

8. Longato B, Bandoli G, Trovo G, Marasciulo E, Valle G. Inorg. Chem 1995;34:1745-1750.

9. Rauterkus MJ, Krebs B. Angew. Chem., Int. Ed 2004;43:1300-1303.

10. Schweiger M, Yamamoto T, Stang PJ, Bläser D, Boese R. J. Org. Chem 2005;70:4861-4864. [PubMed: 15932331]

11. Brasey T, Scopelliti R, Severin K. Inorg. Chem 2005;44:160-162. [PubMed: 15651854]

12. Chen H, Ogo S, Fish RH. J. Am. Chem. Soc 1996;118:4993-5001.

13. Navarro JAR, Janik MBL, Freisinger E, Lippert B. Inorg. Chem 1999;38:426-432. [PubMed: 11673944] 
14. Navarro JAR, Lippert B. Coord. Chem. Rev 1999;186:653-667.

15. Martin, RB. Metal Ions in Biological Systems. Sigel, H.; Sigel, A., editors. Vol. 32. Marcel Dekker; New York, NY: 1996. p. 61-89.

16. Haring UK, Martin RB. Inorg. Chim. Acta 1983;80:1-5.

17. Uchida K, Toyama A, Tamura Y, Sugimura M, Mitsumori F, Furukawa Y, Takeuchi H, Harada I. Inorg. Chem 1989;28:2067-2073.

18. Wirth W, Blotevogel-Baltronat J, Kleinkes U, Sheldrick WS. Inorg. Chim. Acta 2002;339:14-26.

19. Zhu S, Matilla A, Tercero JM, Vijaragavan V, Walmsley JA. Inorg. Chim. Acta 2004;357:411-420.

20. Rauter H, Hillgeris EC, Erxleben A, Lippert B. J. Am. Chem. Soc 1994;116:616-624.

21. Schenetti L, Bandoli G, Dolmella A, Trovo G, Longato B. Inorg. Chem 1994;33:3169-3176.

22. Shen W-Z, Gupta D, Lippert B. Inorg. Chem 2005;44:8249-8258. [PubMed: 16270962]

23. Longato B, Pasquato L, Mucci A, Schenetti L, Zangrando E. Inorg. Chem 2003;42:7861-7871. [PubMed: 14632502]

24. Kubota Y, Biradha K, Fujita M, Sakamoto S, Yamaguchi K. Bull. Chem. Soc. Jpn 2002;75:559-565.

25. Kumazawa K, Yamanoi Y, Yoshizawa M, Kusukawa T, Fujita M. Angew. Chem. Int. Ed 2004;43:5936-5940.

26. Yoshizawa M, Kusukawa T, Fujita M, Sakamoto S, Yamaguchi K. J. Am. Chem. Soc 2001;123:10454-10459. [PubMed: 11673975]

27. Fujita M, Yazaki J, Ogura K. Tetrahedron Lett 1991;32:5589-5592.

28. Walmsley, JA.; Zhu, S. $60^{\text {th }}$ Southwest Regional Meeting of the American Chemical Society. Ft. Worth, TX.: 2004. Abstracts

29. Tercero-Moreno JM, Matilla-Hernandez A, Gonzalez-Garcia S, Niclos-Guiterrez J. Inorg. Chim. Acta 1996;253:23-29.

30. Tercero JM, Matilla A, Sanjuan MA, Moreno CF, Martin JD, Walmsley JA. Inorg. Chim. Acta 2003;342:77-87.

31. Sheldrick GM. Acta Crystallogr., Sect. A 1990;46:467.

32. Sheldrick, GM. SHELXL-97. Program for the Refinement of Crystal Structures. University of Goettingen; Goettingen, Germany: 1997.

33. Spek, AL. PLATON. A Multipurpose Crystallographic Tool. Utrecht University; Utrecht, The Netherlands: 2007.

34. Sigel H, Massoud SS, Song B, Griesser R, Knobloch B, Operschall BP. Chem.-Eur. J 2006;12:81068122.

35. Fletcher TM, Walmsley JA. J. Inorg. Biochem 1997;68:239-249.

36. Albrecht M, Blau O, Fröhlich R. Proc. Natl. Acad. Sci. U.S.A 2002;99:4867-4872. [PubMed: 11959938]

37. Kubota Y, Sakamoto S, Yamaguchi K, Fujita M. Proc. Natl. Acad. Sci. U.S.A 2002;99:4854-4856. [PubMed: 11959936]

38. Brasey T, Scopelliti R, Severin K. Chem. Commun 2006:3308-3310.

39. Lee SB, Hwang S, Chung DS, Yun H, Hong J-I. Tetrahedron Lett 1998;39:873-876.

40. Gorenstein, DG. Phosphorus-31 NMR. Gorenstein, DG., editor. Academic Press; New York: 1984. p. 11

41. Gorenstein DG. J. Amer. Chem. Soc 1975;97:897-900.

42. Smith RM, Alberty RA. J. Phys. Chem 1956;60:180-184.

43. Walmsley JA, Burnett JF. Biochemistry 1999;38:14063-14068. [PubMed: 10529253]

44. Odoko M, Okabe N. Acta Crystallogr. Sect. C 2006;62:m136-m139. [PubMed: 16598121]

45. Barnham KJ, Bauer CJ, Djuran MI, Mazid MA, Rau T, Sadler PJ. Inorg. Chem 1995;34:2826-2832. 


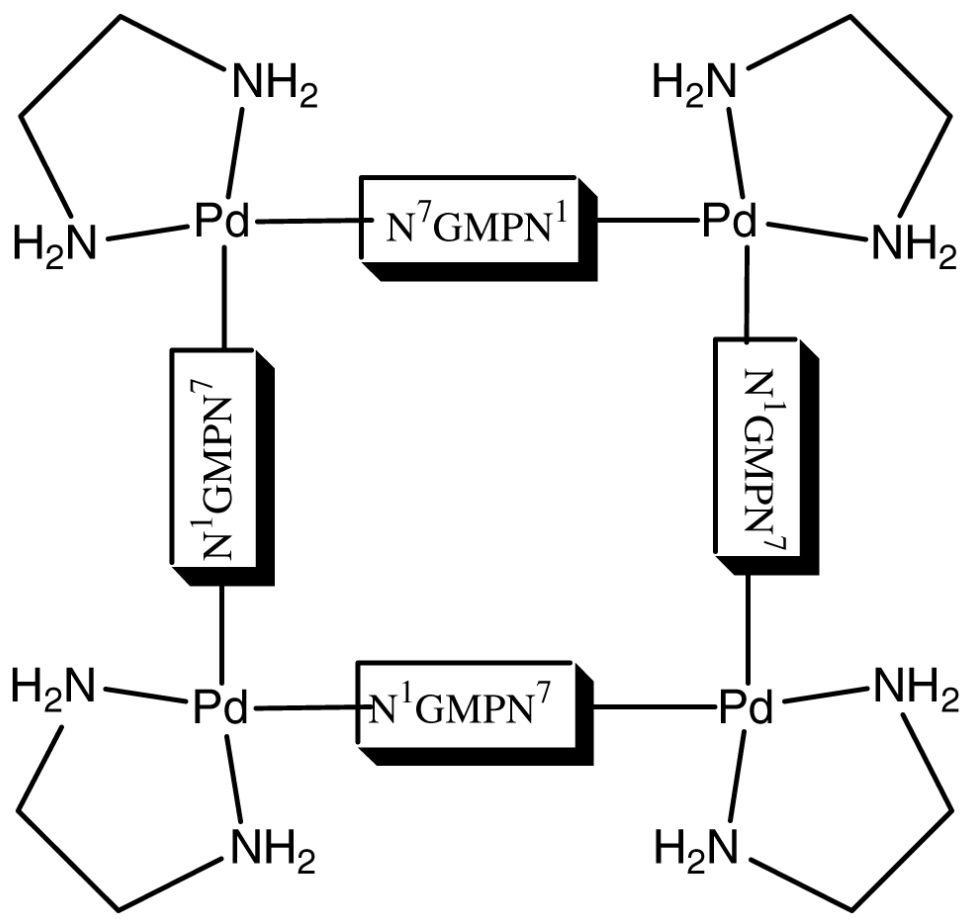

Figure 1.

Structure of $\left[\mathrm{Pd}(\mathrm{en})\left(5^{\prime} \mathrm{GMP}\right)\right]_{4}$ 


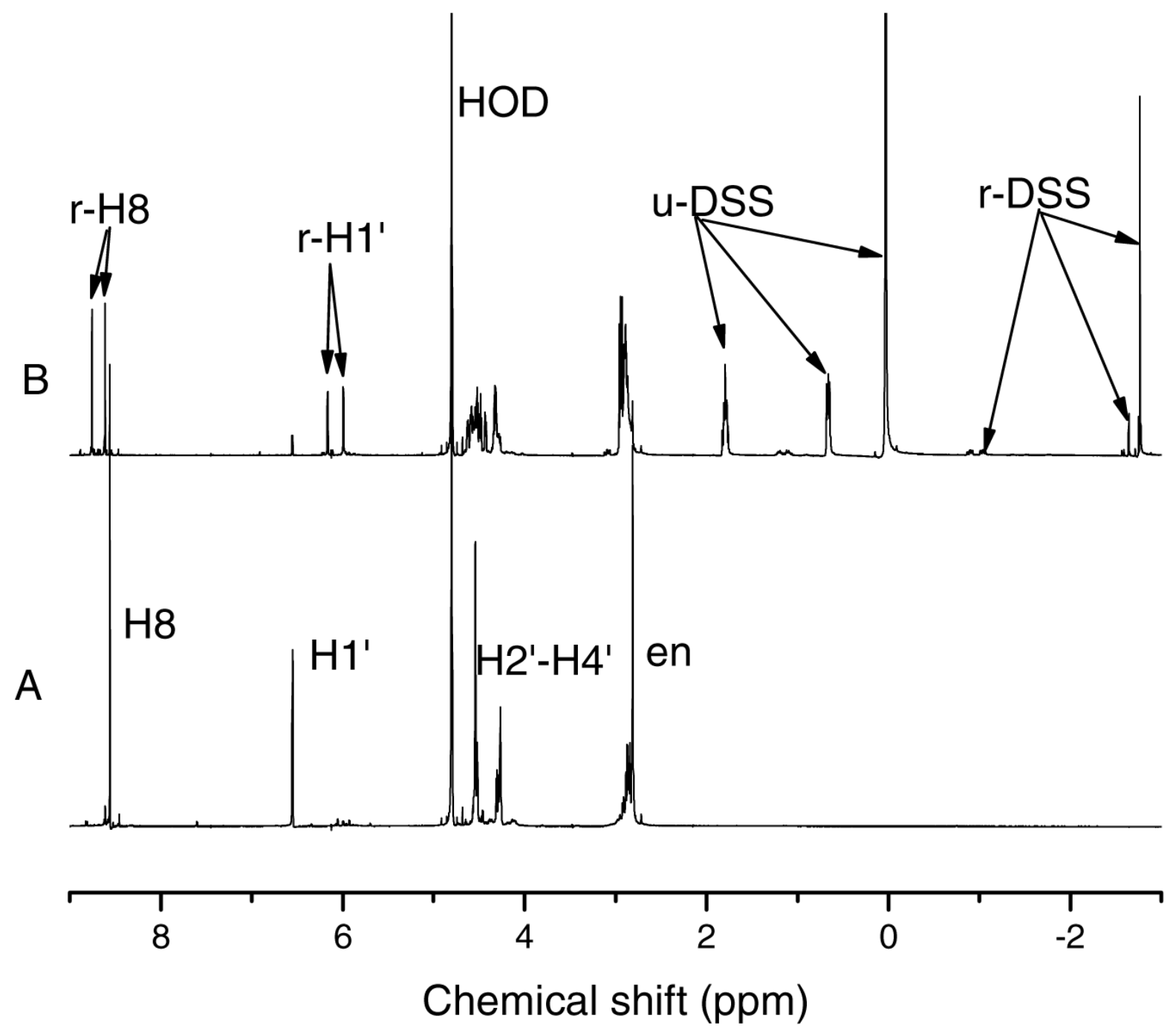

Figure 2.

${ }^{1} \mathrm{H}$ NMR spectra in $\mathrm{D}_{2} \mathrm{O}$ at pD 5.4 and $25^{\circ} \mathrm{C}$; (A) $\left[\mathrm{Pd}(\mathrm{en})\left(5^{\prime} \mathrm{GMP}\right)\right]_{4}(20 \mathrm{mM}$ total $\mathrm{Pd}(\mathrm{II}))$; (B) mixture of $\left[\mathrm{Pd}(\mathrm{en})\left(5^{\prime} \mathrm{GMP}\right)\right]_{4}$ and $\left\{\left[\mathrm{Pd}(\mathrm{en})\left(5^{\prime} \mathrm{GMP}\right)\right]_{6}-\mathrm{DSS}\right\}(20 \mathrm{mM}$ total Pd(II)); ' $\mathrm{r}$ ' stands for hexamer host-guest complex, 'u' stands for free guest ion. 


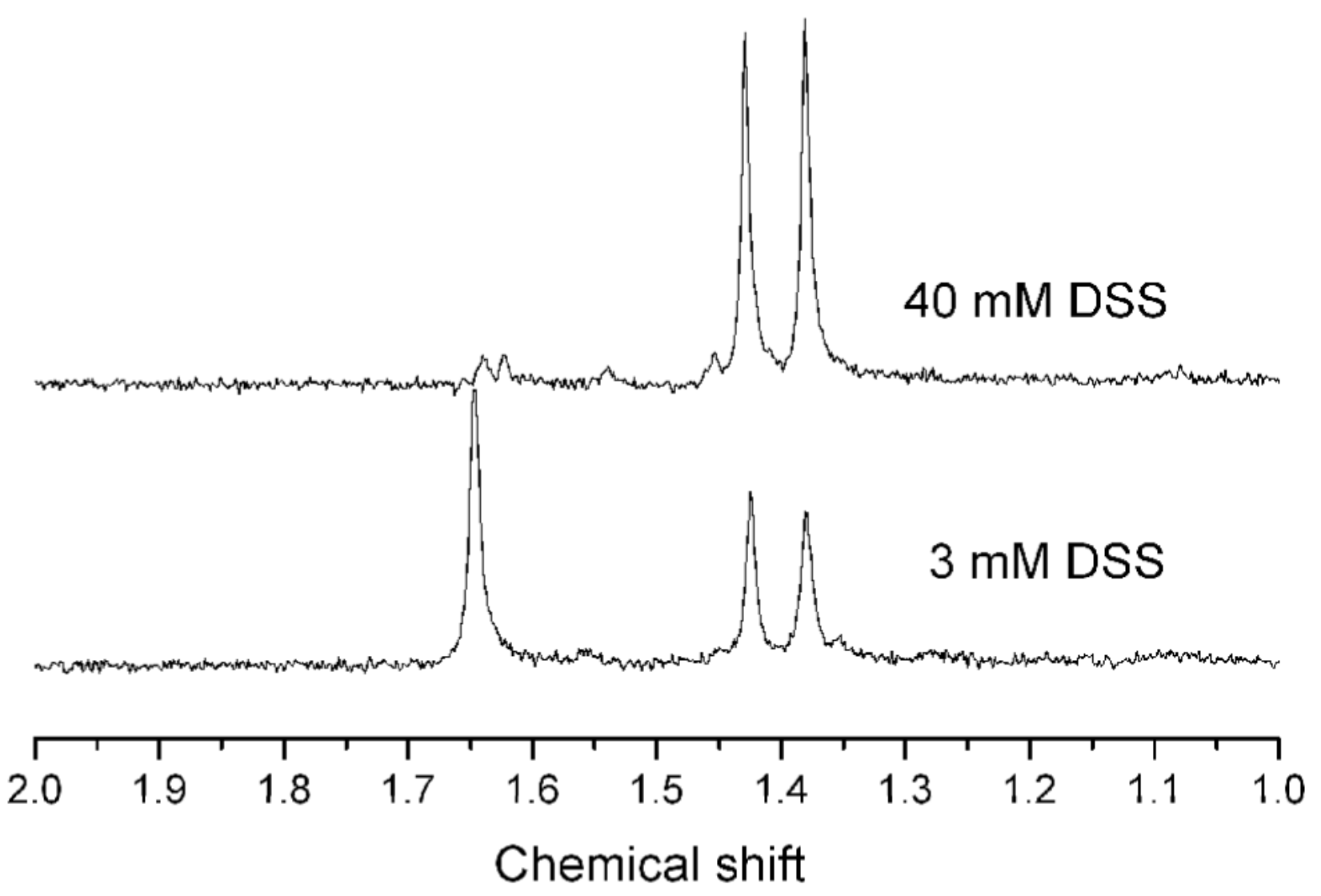

Figure 3.

${ }^{31} \mathrm{P}$ NMR of $30 \mathrm{mM} \mathrm{Pd}(\mathrm{en})\left(5^{\prime} \mathrm{GMP}\right)$ in $\mathrm{D}_{2} \mathrm{O}(30 \mathrm{mM}$ total $\mathrm{Pd}(\mathrm{II}))$ with two different concentrations of DSS, pD 5.5; single line at 1.65 ppm is tetramer and two lines at 1.35-1.45 ppm are hexamer with DSS guest. 


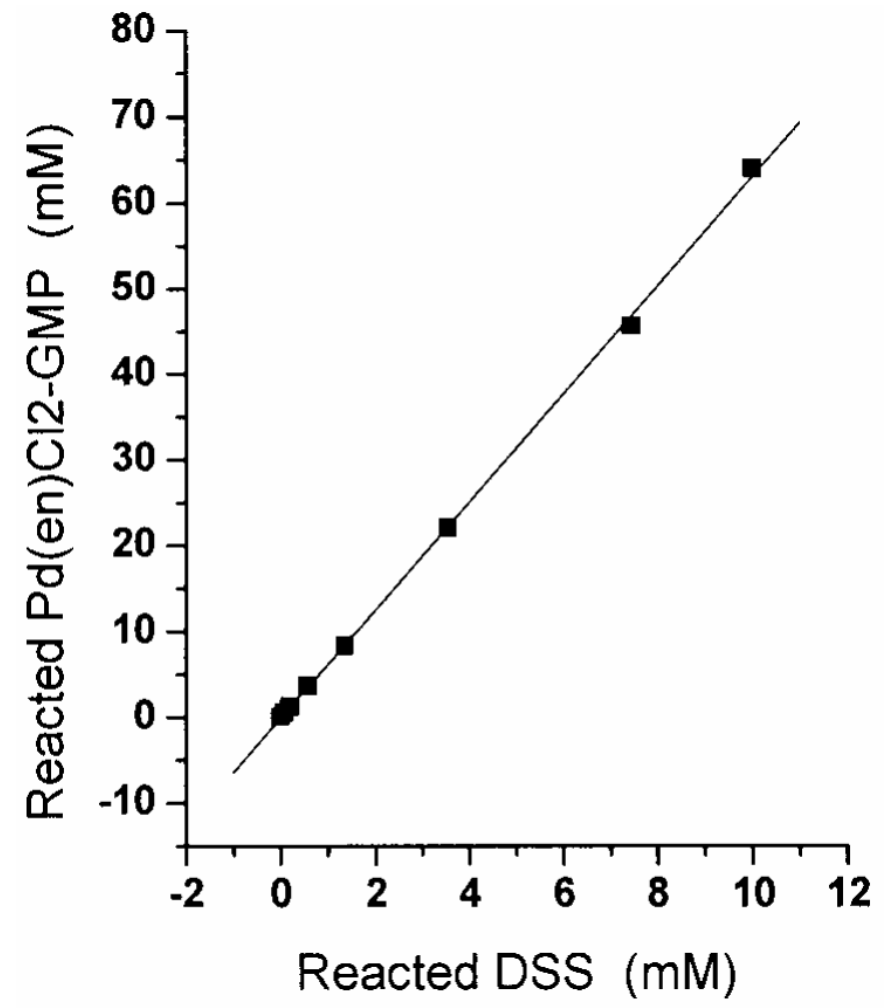

Figure 4.

Determination of $\mathrm{Pd}(\mathrm{en})\left(5^{\prime} \mathrm{GMP}\right)$ : DSS ratio in $\mathrm{D}_{2} \mathrm{O}$ at $\mathrm{pD} 5.4$ by ${ }^{1} \mathrm{H}$ NMR integrated intensity of the $\mathrm{H} 1^{\prime}$ of host $\left[\mathrm{Pd}(\mathrm{en})\left(5^{\prime} \mathrm{GMP}\right)\right]_{6}$ and methyl protons of guest DSS; $10 \mathrm{mM}$ total Pd(II) plus variable amounts of DSS. 


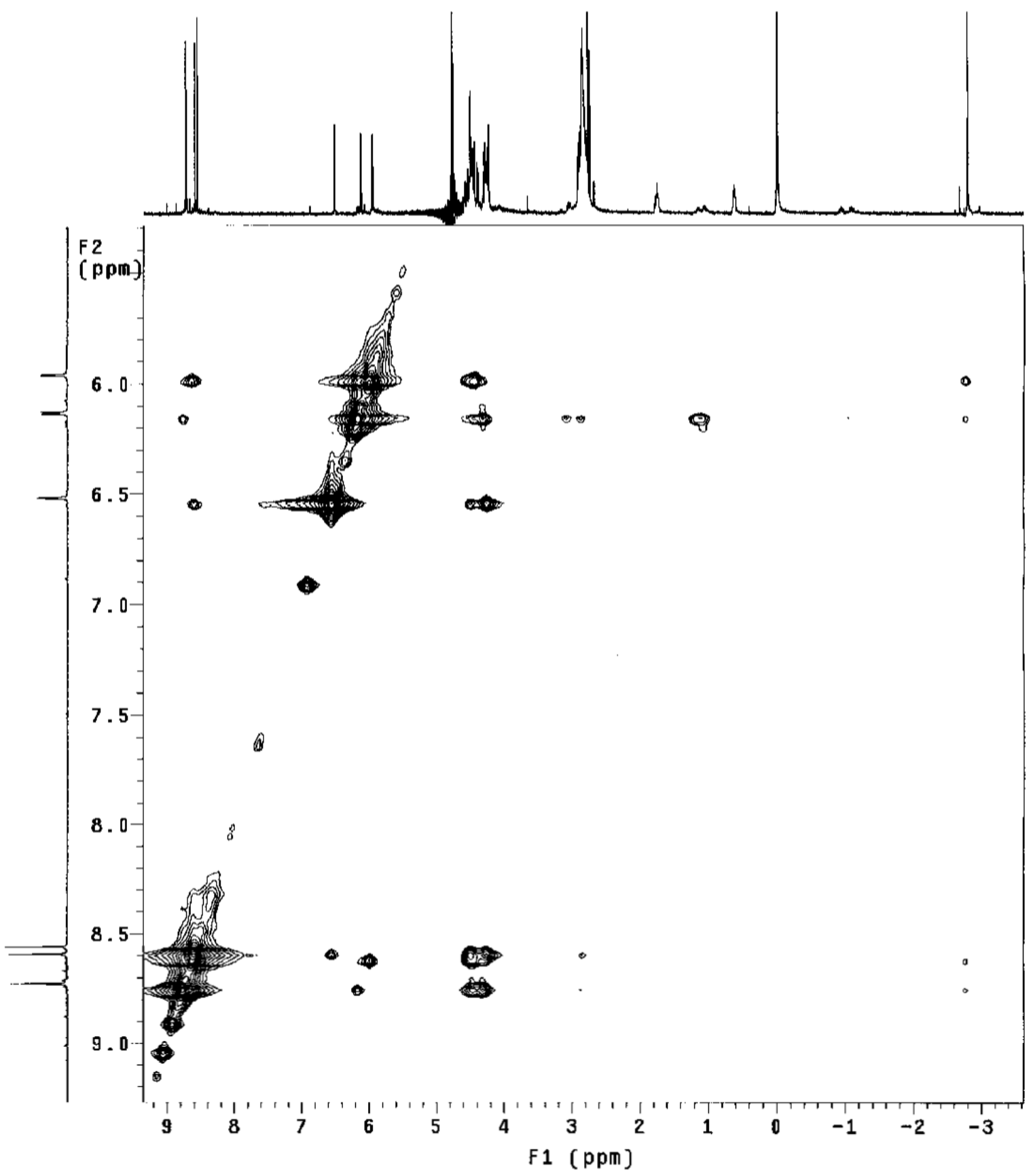

Figure 5.

Partial ${ }^{1} \mathrm{H}$ NOESY spectrum of $\left[\mathrm{Pd}(\mathrm{en})\left(5^{\prime} \mathrm{GMP}\right)\right]_{\mathrm{n}}(19 \mathrm{mM}$ total Pd(II)) with $5 \mathrm{mM}$ DSS in $\mathrm{D}_{2} \mathrm{O}$ at $\mathrm{pD} 5.7$ and $25^{\circ} \mathrm{C}$. 


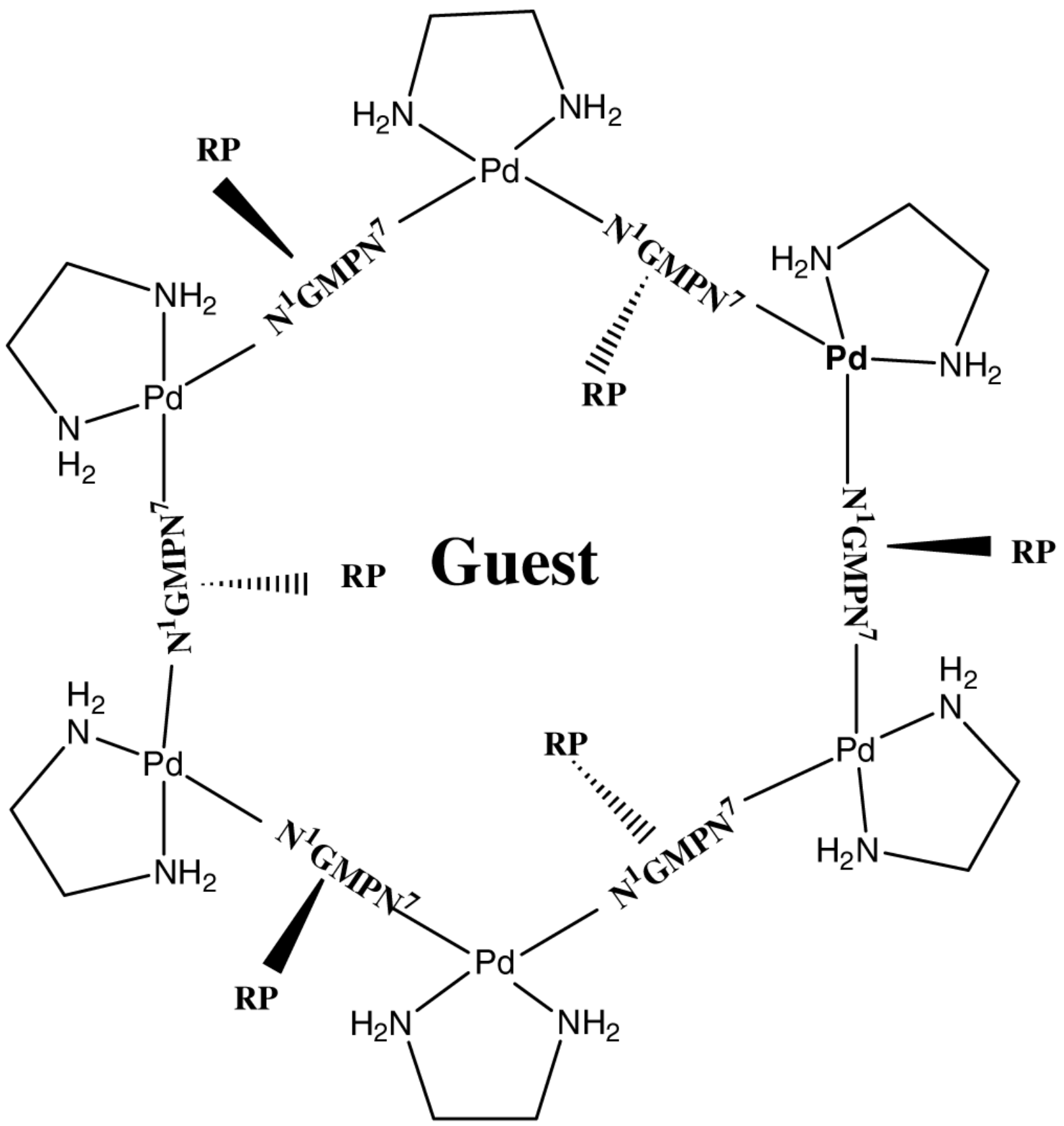




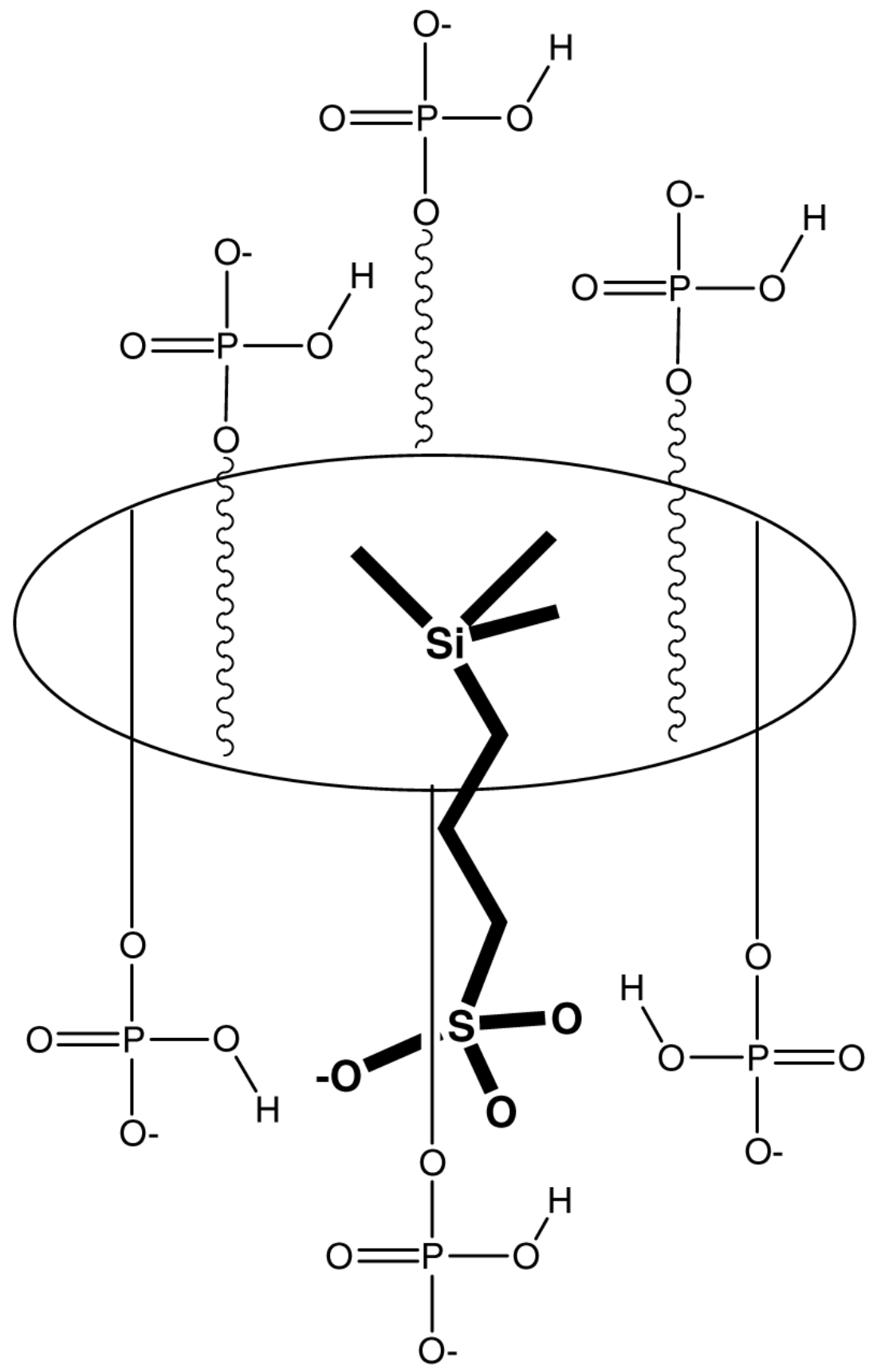

Figure 6.

Figure 6A. Proposed structure for the hexamer. The $5^{\prime} \mathrm{GMP}$ units are alternately pointing up and down around the ring.

Figure $6 \mathrm{~B}$. Schematic drawing of $\left[\mathrm{Pd}(\mathrm{en})\left(5^{\prime} \mathrm{GMP}\right)\right]_{6}$ with DSS guest. The oval represents the $\operatorname{Pd}(e n)$ (guanine) and the vertical solid and wavy lines represent the ribose group. Water molecules may mediate $\mathrm{H}$-bonding between phosphate anions, and between phosphate and sulfonate groups. 

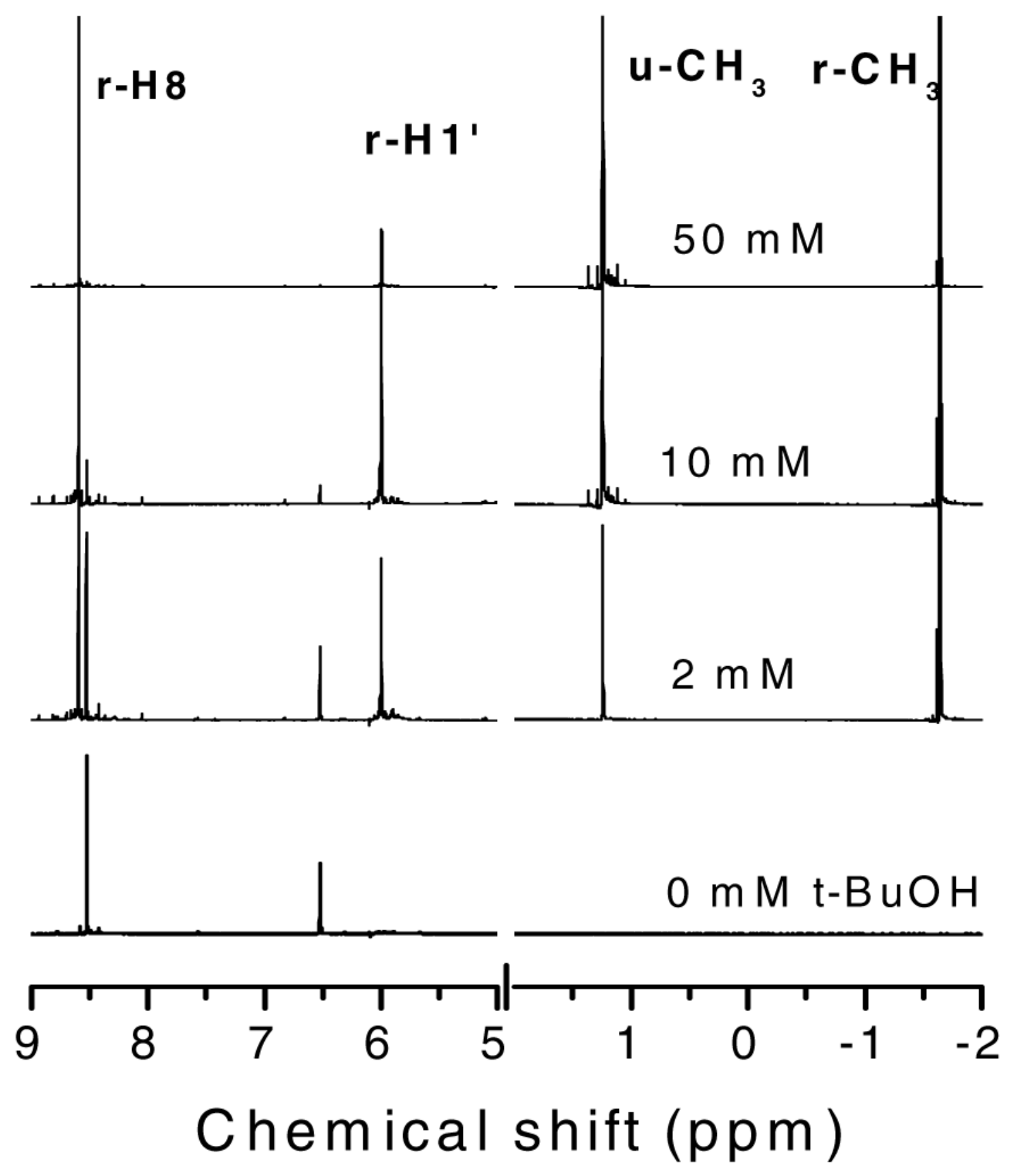

Figure 7.

${ }^{1} \mathrm{H}$ NMR spectra of $\mathrm{Pd}(\mathrm{en})\left(5^{\prime} \mathrm{GMP}\right)(20 \mathrm{mM}$ total $\mathrm{Pd}(\mathrm{II}))$ and $t$-butanol in $\mathrm{D}_{2} \mathrm{O}$ at $\mathrm{pD} 5.4$ and $25^{\circ} \mathrm{C}$. The ' $\mathrm{u}$ ' stands for the resonance from methyl protons of free $t$-butanol, and ' $\mathrm{r}$ ' stands for methyl protons of guest or $\mathrm{H} 8$ and $\mathrm{H}^{\prime}$ ' of hexamer. 


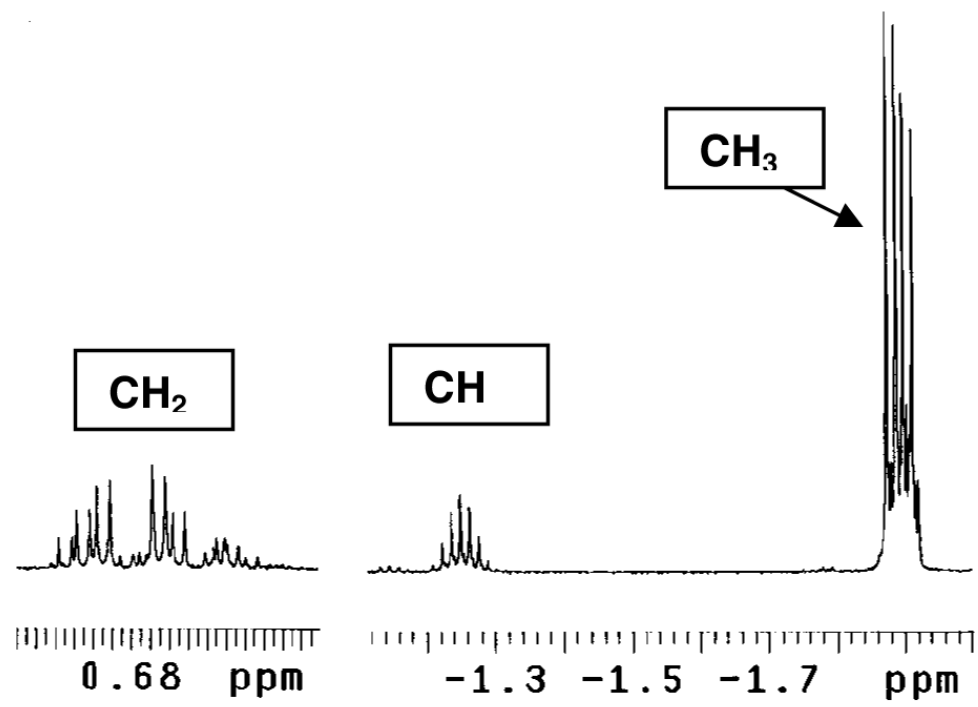

Figure 8.

${ }^{1} \mathrm{H}$ NMR resonances of $i$-butanol as guest in $\left[\mathrm{Pd}(\mathrm{en})\left(5^{\prime} \mathrm{GMP}\right)\right]_{6}$ in $\mathrm{D}_{2} \mathrm{O}$ at pD 5.4 and $26{ }^{\circ} \mathrm{C}$; (20 $\mathrm{mM}$ total $\mathrm{Pd}(\mathrm{II})$ and $10 \mathrm{mM}$ total $i$-butanol). 




Figure 9.

${ }^{1} \mathrm{H}$ NMR spectra in $\mathrm{D}_{2} \mathrm{O}$ at $25^{\circ} \mathrm{C}$. (A) $25 \mathrm{mM}$ Pd(dapol)(5'GMP), pD 5.4 (25 mM total Pd (II)); (B) mixture of (A) and [Pd(dapol)(5'GMP) $]_{6}-2-\mathrm{PrOH}(20 \mathrm{mM}$ total Pd(II), $1.5 \mathrm{mM} 2-$ $\mathrm{PrOH}), \mathrm{pD}$ 5.8. 'react' refers to the host-guest complex. 


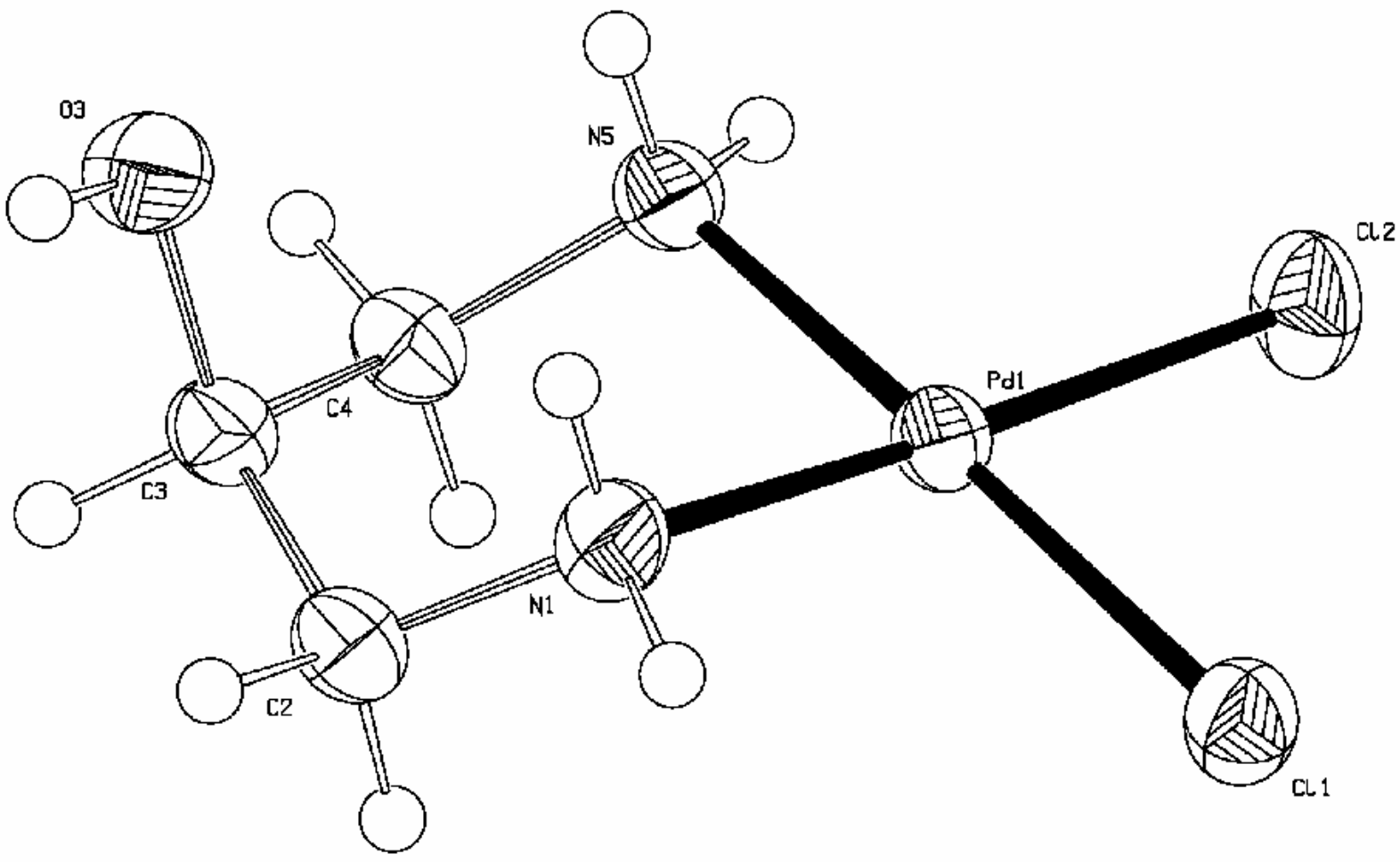

Figure 10.

ORTEP drawing of $\left[\mathrm{Pd}(\right.$ dapo $\left.) \mathrm{Cl}_{2}\right]$ with the atomic numbering scheme; displacement ellipsoids are shown at the $50 \%$ level. 
Table 1

Crystallographic Data for $\left[\mathrm{Pd}(\mathrm{dapol}) \mathrm{Cl}_{2}\right]$.

\begin{tabular}{|c|c|}
\hline Chemical formula & $\mathrm{C}_{3} \mathrm{H}_{10} \mathrm{Cl}_{2} \mathrm{~N}_{2} \mathrm{OPd}$ \\
\hline fw & 267.43 \\
\hline crystal size & $0.57 \times 0.23 \times 0.04 \mathrm{~mm}$ \\
\hline space group & $P 2_{1} / n$ \\
\hline $\mathrm{a}$ & $8.533(2)$ \\
\hline $\mathrm{b}$ & $8.766(2)$ \\
\hline $\mathrm{c}$ & $10.749(2)$ \\
\hline$\alpha=\gamma$ & $90 \mathrm{deg}$ \\
\hline$\beta$ & 105.01(3) \\
\hline Z & 4 \\
\hline $\mathrm{T}$ & 293(2) K \\
\hline$\lambda$ & $0.71073 \AA$ \\
\hline$\mu(\mathrm{Mo}-\mathrm{K} \alpha)$ & $3.002 \mathrm{~mm}^{-1}$ \\
\hline reflections collected & 5586 \\
\hline independent reflections & 2818 \\
\hline $\mathrm{R}_{1}$ & 0.0321 \\
\hline $\mathrm{wR}_{2}$ & 0.0529 \\
\hline
\end{tabular}




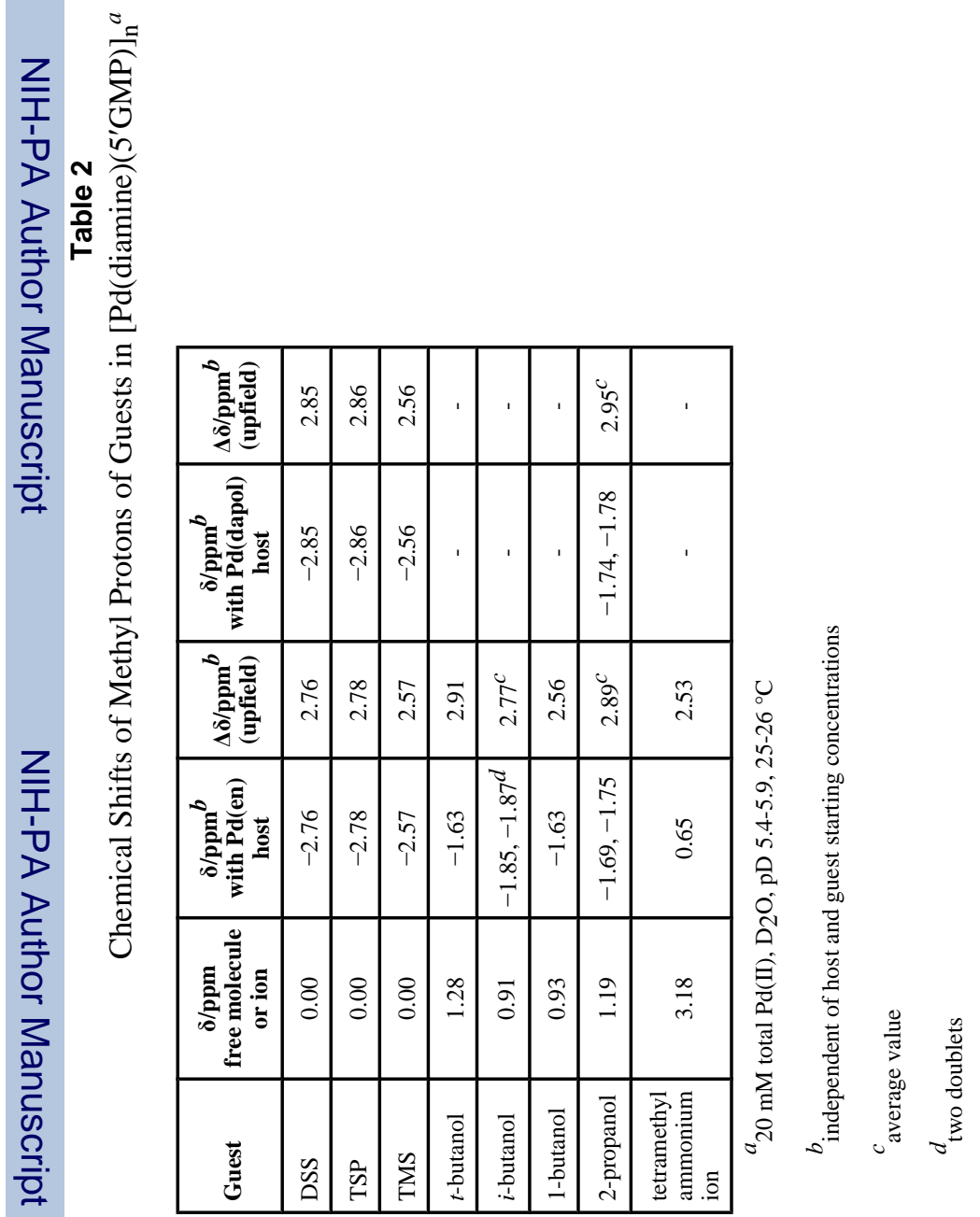




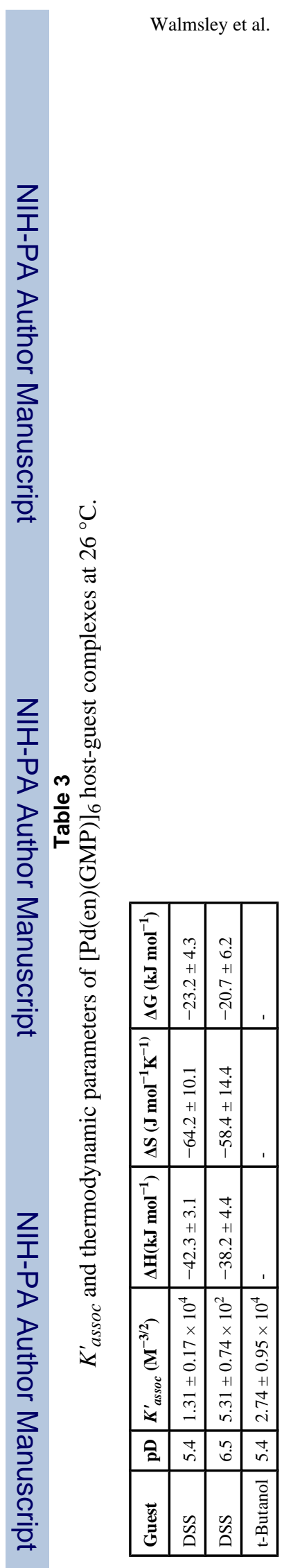

Page 24 
Table 4

Selected Bond Lengths $(\AA)$ and Angles (deg) for [Pd(dapol)Cl $\left.\mathrm{Cl}_{2}\right]$.

\begin{tabular}{|c|c|c|c|}
\hline $\operatorname{Pd}(1)-\mathrm{N}(1)$ & $2.039(2)$ & $\operatorname{Pd}(1)-\mathrm{N}(5)$ & $2.035(2)$ \\
\hline $\operatorname{Pd}(1)-\mathrm{Cl}(1)$ & $2.3096(11)$ & $\mathrm{Pd}(1)-\mathrm{Cl}(2)$ & $2.3027(9)$ \\
\hline $\mathrm{N}(1)-\mathrm{Pd}(1)-\mathrm{Cl}(2)$ & $177.59(7)$ & $\mathrm{N}(5)-\mathrm{Pd}(1)-\mathrm{Cl}(1)$ & $178.54(7)$ \\
\hline $\mathrm{N}(1)-\mathrm{Pd}(1)-\mathrm{Cl}(1)$ & $88.90(7)$ & $\mathrm{N}(5)-\mathrm{Pd}(1)-\mathrm{Cl}(2)$ & $89.36(7)$ \\
\hline $\mathrm{N}(1)-\mathrm{Pd}(1)-\mathrm{N}(5)$ & $88.74(10)$ & $\mathrm{Cl}(1)-\mathrm{Pd}(1)-\mathrm{Cl}(2)$ & $92.01(3)$ \\
\hline
\end{tabular}


Hydrogen Bond Geometry $(\AA)$

\section{Table 5}

\begin{tabular}{llc}
\hline $\boldsymbol{D}-\mathbf{H}---\boldsymbol{A}$ & $\boldsymbol{D}--\boldsymbol{A}$ & $\boldsymbol{D}-\mathbf{H}--\boldsymbol{A}$ \\
\hline $\mathrm{N}(5)-\mathrm{H}(5 \mathrm{~B})--\mathrm{Cl}(1) \# 1$ & $3.546(3)$ & 152.7 \\
$\mathrm{~N}(5)-\mathrm{H}(5 \mathrm{~A})--\mathrm{O}(3) \# 2$ & $2.978(3)$ & 141.5 \\
$\mathrm{O}(3)-\mathrm{H}(3 \mathrm{~A})--\mathrm{Cl}(1) \# 3$ & $3.386(2)$ & 127.9 \\
$\mathrm{O}(3)-\mathrm{H}(3 \mathrm{~A})$--- $\mathrm{Cl}(1) \# 4$ & $3.261(2)$ & 143.2 \\
$\mathrm{~N}(1)-\mathrm{H}(1 \mathrm{~B})--\mathrm{Cl}(2) \# 4$ & $3.396(3)$ & 159.5 \\
$\mathrm{~N}(1)-\mathrm{H}(1 \mathrm{~A})--\mathrm{O}(3) \# 5$ & $3.378(4)$ & 167.1 \\
\hline
\end{tabular}

